community. The opposite is almost certainly true. More full time medical directors and consultants of high calibre will coordinate district terminal care services and improve undergraduate and postgraduate education. More general practitioner and medical rotations will incorporate some palliative medicine, while registrar rotations with other specialties, particularly radiotherapy and oncology, will become inevitable. These activities will raise the status of part time palliative care physicians as they develop a full range of services and participate in education and research.

Finally, recognition brings with it responsibilities. Doctors and others working in palliative medicine must continue to plan services, strive for long term funding, and be willing to submit themselves to audit and peer review. Only thus may the new specialty speak with authority.

Consultant Physician in Palliative Medicine,

RICHARD HILLIER

Countess Mountbatten House,

Southampton University Teaching Hospitals,

Southampton $\mathrm{SO} 33 \mathrm{JB}$

1 Melvin JL. Interdisciplinary and multidisciplinary activities and the ACRM. Arch Phys Med Rehabil 1980;61:379-80.

2 Department of Health and Social Services. Health services development: terminal care. Heywood, Lancashire: Health Publications Unit, 1987. (HC/87/4 and LAC/87/2.)

3 McIllmurray MB. District cancer physicians: report of a working group of the Association of Cancer Physicians. $\mathcal{F} R$ Coll Physicians Lond 1987;21:117-21.

\title{
An inspector calls
}

\section{An NHS inspectorate will work only with better routine clinical data}

In its recent evidence to the government's review of the National Health Service the National Association of Health Authorities called for a national inspectorate to ensure that all hospitals meet required standards. ${ }^{1}$ The Bow Group, a conservative think tank, has also just published Inspect Health, which makes the case for an inspectorate ${ }^{2}$ and last week the idea was boosted by the Labour party ( $p 000)$. The idea is not new. It was suggested by the Ministry of Health in $1944^{3}$ and more recently appeared in the Department of Health and Social Security's document Patients First. ${ }^{+}$ Although previous considerations have come to little, the likelihood that internal marketing will be introduced soon suggests that the idea of an inspectorate should be taken more seriously this time. And even if health authorities maintain their virtual monopoly of supplying services there is a growing demand for an increase in their accountability to the public.

An inspectorate is an expert group that is independent of those responsible for providing a service whose assessment is based on widely accepted, explicit criteria and standards. There is less agreement about whether it should be able to apply or threaten sanctions or simply be limited to offering advice. We may learn something about the effectiveness of inspectorates by looking at those that already exist both in Britain and abroad.

Since 1973 the Joint Commission on Accreditation of Hospitals in the United States has made medical audit in hospitals a precondition for reimbursement from major insurance companies and from federal and state governments. In addition, the professional review organisations require assurance that federally funded services are medically necessary, meet professionally recognised standards of quality, and are of a proper degree of care and duration. Although these inspectorates are able to identify deficiencies in care, there is little evidence that they have improved professional competence. ${ }^{5}$

In Britain the various environmental inspectorates responsible for such measures as fire and radiation safety and food hygiene have been effective in improving conditions. Their tasks are, however, considerably easier than those envisaged by the National Association of Health Authorities for inspecting health services. A better model is the Health Advisory Service, established in 1969 to review and advise on local NHS provision for the elderly and mentally ill, although it is not strictly an inspectorate in that its views are based on implicit professional judgments rather than on explicit criteria. Analysing the 35 reports on services for the elderly undertaken by the Health Advisory Service between 1985 (when their reports first became public) and 1987, the authors of a recent review found that "remarkably little appears to have changed since 1969" as regards inpatient services: two thirds of buildings were unsuitable and decaying; three fifths of wards and day rooms were overcrowded; three quarters of hospitals had inadequate sanitary conditions; three quarters used restraint excessively; and $90 \%$ had inadequate or inappropriate staffing. ${ }^{6}$ Community services fared little better. Indeed, so similar were the reports on local services in various areas that the authors half in jest suggest that an all purpose report with standard recommendations could be issued to districts, thus saving the $£ 1 \mathrm{~m}$ a year spent visiting.

What may Mrs Thatcher learn from the experiences of the Health Advisory Service as she contemplates the National Association of Health Authorities' suggestion? One important lesson is that without explicit criteria and standards an inspectorate is unable to monitor performance and may undertake only disaster spotting. Even if inspection based on criteria and standards were established it would be largely restricted to the assessing of inputs, such as the state of buildings, and of processes, such as waiting times in outpatient departments and the length of stays of inpatients. Such restrictions are not inevitable but reflect the current range and quality of routine health service information. Until there is a dramatic improvement in clinical information (which will require more radical changes than those that will result from implementing the Körner reports) and a serious investment in the research and development of measures of outcome the role of an inspectorate will remain limited. This is not an argument against establishing an inspectorate but simply a warning that the current limitations of routinely assessing the performance of health services should be recognised if an inspectorate is not to suffer the fate of other initiatives that have become discredited.

NICK BLACK

Senior Lecturer in Health Services Research,

Department of Community Health,

London School of Hygiene and Tropical Medicine, London WC1E 7HT

\footnotetext{
1 National Association of Health Authorities. The nation's health: a way forward. Birmingham: NAHA, 1988.

2 Wynns S. Inspect Health: the case for an inspectorate for the NHS. London: Bow Group, 1988.

3 Ministry of Health. A national health service. London: HMSO, 1944.

4 Department of Health and Social Security. Patients first. London: HMSO, 1979.

Gaumer GL. Regulating health professionals: a review of the empirical literature. Milbank $Q$ 1984;62:380-416.

Day P, Klein R, Tipping G. Inspecting for quality: services for the elderly. Bath: University of Bath, 1988. (Bath Social Policy Paper No 12.)
} 